\title{
Effect of thermal annealing on defects in post- growth hydrogenated GaNP
}

Daniel Dagnelund, C. W. Tu, A. Polimeni, M. Capizzi, Weimin Chen and Irina Buyanova

\section{Linköping University Post Print}

\section{Tweet}

N.B.: When citing this work, cite the original article.

Original Publication:

Daniel Dagnelund, C. W. Tu, A. Polimeni, M. Capizzi, Weimin Chen and Irina Buyanova, Effect of thermal annealing on defects in post-growth hydrogenated GaNP, 2013, Physica Status Solidi. C, Current topics in solid state physics, (10), 4, 561-563.

http://dx.doi.org/10.1002/pssc.201200353

Copyright: (C) 2013 WILEY-VCH Verlag GmbH \& Co. KGaA, Weinheim

Postprint available at: Linköping University Electronic Press http://urn.kb.se/resolve?urn=urn:nbn:se:liu:diva-93873 


\title{
Effect of thermal annealing on defects in post-growth hydrogenated GaNP
}

\author{
D. Dagnelund ${ }^{1}$, C. W. Tu$^{2}$, A. Polimeni ${ }^{3}$, M. Capizzi ${ }^{3}$, W. M. Chen ${ }^{1}$ and I. A. Buyanova ${ }^{*}, 1$ \\ ${ }^{1}$ Department of Physics, Chemistry and Biology, Linköping University, S-581 83 Linköping, Sweden \\ ${ }^{2}$ Department of Electrical and Computer Engineering, University of California, La Jolla, California 92093, USA \\ ${ }^{3}$ Dipartimento di Fisica and INFM, Università di Roma "La Sapienza”, Piazzale A. Moro 2, I-00185 Roma, Italy
}

Received ZZZ, revised ZZZ, accepted ZZZ

Published online ZZZ (Dates will be provided by the publisher.)

Keywords (ODMR, dilute nitrides, Ga interstitial, post-growth hydrogenation, annealing)

* Corresponding author: e-mail irb@ifm.liu.se, Phone: +46 132817 45, Fax: +46 13137568

Effect of thermal annealing on paramagnetic centers in post-growth hydrogenated $\mathrm{GaN}_{0.0081} \mathrm{P}_{0.9919}$ epilayer is examined by means of photoluminescence and optically detected magnetic resonance (ODMR) techniques. In recent studies, several Ga-interstitial $\left(\mathrm{Ga}_{\mathrm{i}}\right)$ related centers were found to be activated by the presence of hydrogen in the hydrogenated GaNP alloys. These centers compete with near-band edge radiative recombination. Annealing at $400^{\circ} \mathrm{C}$ in Ar-ambient is found to cause quenching of the $\mathrm{Ga}_{\mathrm{i}}$-related ODMR signals that were activated by post-growth hydrogenation. We tentatively ascribe this effect to dissociation of the $\mathrm{H}-\mathrm{Ga}_{\mathrm{i}}$ complexes and subsequent out-diffusion of $\mathrm{H}$.
1 Introduction Hydrogen is commonly present impurity in most steps of semiconductor growth and postgrowth processing. Due to its high chemical reactivity, $\mathrm{H}$ has been used for decades to passivate harmful defects in semiconductors [1-8]. In some rare cases, $H$ was also found to activate defects [9-10].

Hydrogen is also commonly present during growth of GaNP alloys that are promising materials [11] for fabrication of light sources that are lattice matched to $\mathrm{Si}$, a key component lacking today in Si-based optoelectronics. Incorporation of nitrogen introduces a quasi-direct band gap [12] which leads to increase the light emission intensity required for fabrication of effective visible light emitting devices.

Unfortunately, dilute nitrides suffer from point defects which degrade the optical and electrical quality of the material by e.g. introducing competing recombination channels that are mainly non-radiative. Post-growth hydrogenation was first considered as a possible way of improving the luminescence properties. Instead, it was found that $\mathrm{H}$ greatly affects band structure of GaNP alloys [11] which was understood in terms of $\mathrm{H}$-induced passivation of $\mathrm{N}$ that caused a decrease of the effective $\mathrm{N}$ content [13-14]. On the other hand, studies related to effects of $\mathrm{H}$ on optical quality and non-radiative recombination centers in dilute nitrides are rather limited [15]. Recently, we analyzed effects of $\mathrm{H}$ treatment on defects in both GaNP and GaNAs $[16,17]$. In the case of GaNAs, hydrogenation was found to efficiently passivate all paramagnetic centers that have a $\mathrm{Ga}$ interstitial atom $\left(\mathrm{Ga}_{\mathrm{i}}\right)$ at their core. This is the expected effect of $\mathrm{H}$ acting as a defect passivator. In GaNP, on the other hand, post-growth hydrogenation efficiently activated several paramagnetic centers related to $\mathrm{Ga}_{\mathrm{i}}$. These centers were found to efficiently compete with the radiative recombination reducing its efficiency [16]. Since none of these $\mathrm{Ga}_{\mathrm{i}}$-related defects were previously detected in GaNP, the activation was tentatively attributed to the formation of $\mathrm{Ga}_{\mathrm{i}}-\mathrm{H}$ complexes.

It is well known that all $\mathrm{H}$-induced modifications of band structure of GaNP are fully reversed upon removal of $\mathrm{H}$ by thermal annealing at temperatures above $400{ }^{\circ} \mathrm{C}$ [13]. However, effects of such out-diffusion of $\mathrm{H}$ on defect properties of GaNP remain unknown. Therefore, the focus of the present study is to examine the effect of thermal annealing on the $\mathrm{Ga}_{\mathrm{i}}-\mathrm{H}$ complexes formed in the hydrogenated GaNP epitaxial layers. Photoluminescence (PL) and optically detected magnetic resonance techniques (ODMR) will be employed for these purposes. 
2 Experimental details A-250 nm thick GaNP epitaxial layer with $\mathrm{N}$ composition of $0.81 \%$ was studied. It was grown at $520^{\circ} \mathrm{C}$ on a GaP substrate by means of gas source molecular beam epitaxy. Postgrowth hydrogenation was preformed at $300{ }^{\circ} \mathrm{C}$ by ion-beam irradiation from a Kaufmann source using a low $\mathrm{H}$ ion energy $(100 \mathrm{eV})$ and a current density of $\sim 10 \mu \mathrm{A} / \mathrm{cm}^{2}$. The $\mathrm{H}$ dose was $1 \times 10^{18}$ ions $/ \mathrm{cm}^{2}$. In order to study the effect of thermal annealing, a piece of the GaNP epitaxial layer was annealed for 60 min at $400{ }^{\circ} \mathrm{C}$ in an $\mathrm{Ar}$ ambient.

PL and ODMR measurements were performed at $5 \mathrm{~K}$ using the $532 \mathrm{~nm}$ line of a solid state laser as an excitation source. PL signals were dispersed by a $0.8 \mathrm{~m}$ double grating monochromator and detected by a $\mathrm{Si}$ photodiode. ODMR signals were measured at X-band $(9.214 \mathrm{GHz})$ as spin-resonance induced changes of the PL intensity and were detected by the lock-in technique in phase with an amplitude modulated microwave field at a frequency of $3333 \mathrm{~Hz}$.

3 Results Figure 1 displays PL spectra taken at $5 \mathrm{~K}$ in the visible spectral range from the investigated samples before and after hydrogenation and also thermal annealing. The emissions originate from radiative recombination at $\mathrm{N}$ related localized states. A blue shift of this emission observed after post-growth hydrogen treatment reflects a partial H-induced recovery of the energy bandgap and can be viewed as a decrease in the effective $\mathrm{N}$ concentration due to bonding of $\mathrm{H}$ to $\mathrm{N}$. In addition, a decrease in the PL intensity is observed. The PL peak position of hydrogenated GaNP can be red shifted to that of the as-grown sample by thermal annealing. This is attributed to breaking of $\mathrm{H}-\mathrm{N}$ bonds and subsequent out-diffusion of $\mathrm{H}$. Moreover, the annealing also causes an increase in the PL intensity. These effects of hydrogenation and annealing on the PL properties are well documented in the literature [11] and, therefore, will not be further discussed in the paper.

In order to understand effects of hydrogenation and annealing on defects in GaNP, ODMR studies were performed. Typical ODMR spectra measured from the investigated samples by monitoring near-band edge PL emissions are shown in Figure 2. The ODMR spectra are found to be isotropic and contain several peaks originated from different defects. The negative sign of the ODMR signals corresponds to a decrease in the visible PL intensity upon spin-resonance enhancement in the defect-mediated carrier recombination, showing that the latter acts as a competing recombination channel for the former. Although ODMR studies cannot give information on the absolute defect concentration, relative strengths of the ODMR signals from different samples can be taken as a measure of the importance of the monitored defects in competing carrier recombination. It can be considered as a measure of relative defect concentrations, enabling a qualitative comparison presented below.

The ODMR signal from the as-grown sample is found to be very weak and consists of a single Lorentzian line

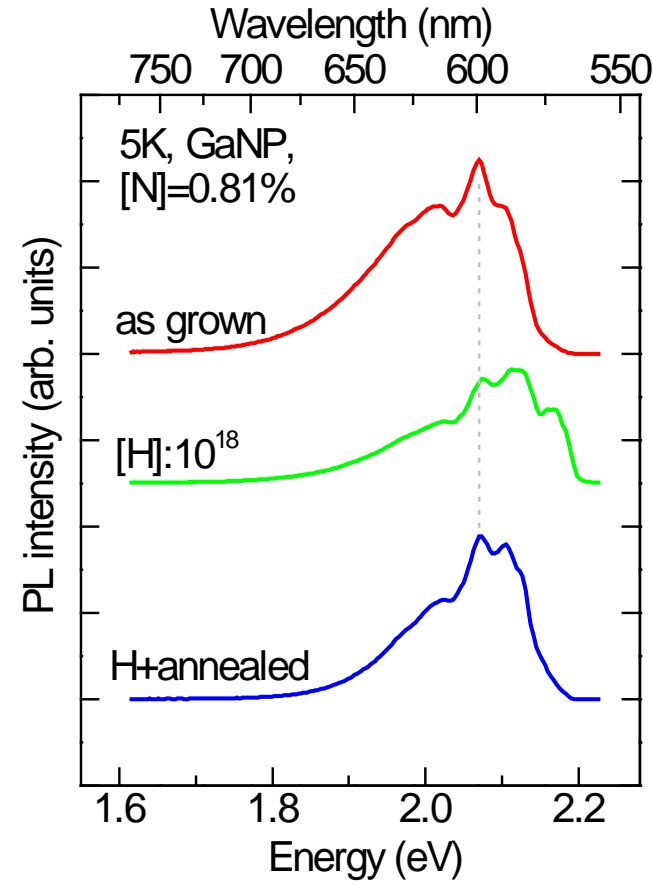

Figure 1 Representative PL spectra obtained at $5 \mathrm{~K}$ from $250 \mathrm{~nm}$ thick $\mathrm{GaN}_{0.0081} \mathrm{P}_{0.9919}$ epitaxial layers. Post-growth hydrogenation causes a blue-shift of the PL peak compared to the as grown sample. Consequent annealing at $400{ }^{\circ} \mathrm{C}$ causes a red-shift of the PL peak position. The dashed gray line is merely a guide for the eyes.

(denoted L2) originating from paramagnetic centers with an effective electron spin $S=1 / 2$ and g-value of $~ 2$. A lack of resolved hyperfine structure hampers chemical identification of these defects. Post-growth hydrogenation caused a dramatic increase of the L2 intensity and an unexpected appearance of a new, strong ODMR signal which spreads over a wide field range. From a comparison with the previously reported data in GaNP [16, 17], these multiple ODMR lines are attributed to a Ga interstitial related complex, previously denoted as $\mathrm{Ga}_{\mathrm{i}}-\mathrm{C}$. The simulated ODMR spectra from the "L2" and $\mathrm{Ga}_{\mathrm{i}}-\mathrm{C}$ are also shown in Fig. 2, using the same spin Hamiltonian parameters as given in Refs. 16 and 17. The agreement between simulation and experimental spectra is satisfactory. The appearance of $\mathrm{Ga}_{\mathrm{i}} \mathrm{-}$ C ODMR signal after hydrogenation was previously attributed to activation of $\mathrm{Ga}_{\mathrm{i}}$-related defects by complexing with $H$ [16]. This causes a change in the energy level position and/or a charge state of the defects, thereby enabling their observation via ODMR. The observed anticorrelation between the ODMR signal intensity and the visible PL intensity signifies the importance of the $\mathrm{Ga}_{\mathrm{i}}$-related defects in competing carrier recombination.

In the case of $\mathrm{H}-\mathrm{N}$ bonding, the $\mathrm{H}$-induced passivation of $\mathrm{N}$ was found to be reversible [13] by thermal annealing treatment at moderate temperatures. This is due to breaking of $\mathrm{H}-\mathrm{N}$ bonds and subsequent out-diffusion of hydrogen. 


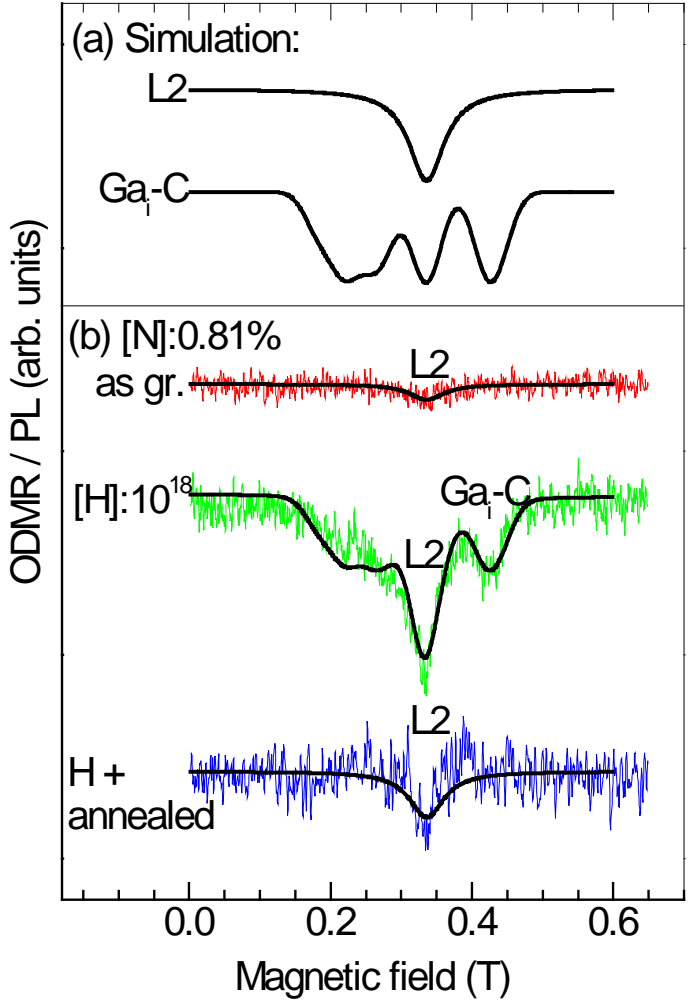

Figure 2 (a) Simulated ODMR spectra of the L2 center and the $\mathrm{Ga}_{\mathrm{i}}-\mathrm{C}$ defect are displayed with the aid of a spin Hamitonian $\mathrm{H}=$ $\mu_{\mathrm{B}}$ gB $\mathbf{S}+$ AS $\cdot \mathbf{I}$. The spin Hamiltonian parameters for the $\mathrm{Ga}_{\mathrm{i}}-\mathrm{C}$ were determined [16] to be effective electron spin $S=1 / 2$, nuclear spin $\mathrm{I}=3 / 2, \mathrm{~g}=2.00 \pm 0.01$, and $\mathrm{A}\left({ }^{69} \mathrm{Ga}\right)=0.062 \pm 0.003 \mathrm{~cm}^{-1}$. The $\mathrm{g}$ value of the defect L2 is deduced [16] to be $1.96 \pm 0.01$. (b) ODMR spectra obtained at $5 \mathrm{~K}$ by monitoring the band-edge emissions in the 550-810 nm range. The ODMR signals are isotropic and are normalized to the PL intensity. Simulated spectra are shown in (b) by thick black lines.

In an attempt to find out weather the $\mathrm{H}$-induced activation of $\mathrm{Ga}_{\mathrm{i}}-\mathrm{C}$ defects can also be reversed, the hydrogenated sample was subjected to post growth thermal annealing treatment. Indeed, annealing of the H-treated sample caused a dramatic quenching of the $\mathrm{Ga}_{\mathrm{i}}-\mathrm{C}$ ODMR signal, accompanied by an increase of the PL intensity. This is interpreted as the evidence for breaking of the $\mathrm{H}-\mathrm{Ga}_{\mathrm{i}}$ bonds and subsequent out-diffusion of $\mathrm{H}$. This also implies that the bonding of $\mathrm{H}$ to the $\mathrm{Ga}_{\mathrm{i}}-\mathrm{C}$ defect is of a comparable strength as that to the $\mathrm{N}$ atoms, as both of them can be dissociated at temperatures of $\sim 400{ }^{\circ} \mathrm{C}$.

4 Conclusion In conclusion, by the detailed ODMR study of GaNP epilayers we have been able to show that $\mathrm{H}$ incorporation leads to activation of a defect which has a $\mathrm{Ga}_{\mathrm{i}}$ atom at its core and may also involve a $\mathrm{H}$ atom as a partner. Subsequent thermal annealing of hydrogenated samples is shown to efficiently suppress the $\mathrm{Ga}_{\mathrm{i}}$-related defects. This effect is tentatively ascribed to dissociation of $\mathrm{H}-\mathrm{Ga}_{\mathrm{i}}$ complexes. The obtained results provide a useful insight into the effect of $\mathrm{H}$ on recombination centers in GaNP, and will hopefully shed light on control of the defects in the GaNP alloys by optimizing post-growth treatments.

Acknowledgements Financial support by the Swedish Research Council (Grant No. 621-2010-3815) is greatly appreciated.

\section{References}

[1] J. Neugebauer and Chris G. Van de Walle, "Semiconductors and Semimetals," in Hydrogen in Semiconductors II, edited by N. H. Nickel (Academic Press, Boston, 1999), Vol. 61.

[2] C. T. Sah, J. Y. C. Sun, and J. J. Tzou, Appl. Phys. Lett. 43, 204 (1983).

[3] J. I. Pankove, D. E. Carlson, J. E. Berkeyheiser, and R. O. Wance, Phys. Rev. Lett. 51, 2224 (1983).

[4] N. M. Johnson, C. Herring, and D. J. Chadi, Phys. Rev. Lett. 56, 769 (1986).

[5] W. M. Chen, I. A. Buyanova, A. Buyanov, T. Lundström, W. G. Bi, and C. W. Tu, Phys. Rev. Lett. 77, 2734 (1996).

[6] I. A. Buyanova, W. M. Chen, G. Pozina, W.-X. Ni, G. V. Hansson, and B. Monemar, Appl. Phys. Lett. 71, 3673 (1997).

[7] A. Buyanova, A. C. Ferreira, P. O. Holtz, B. Monemar, K. Campman, J. L. Merz, and A. C. Gossard, Appl. Phys. Lett. 68, 1365 (1996).

[8] P. Caplan, E. Poindexter, B. Deal, and R. Razouk, J. Appl. Phys. 50, 5847 (1979).

[9] See, e.g., A. Amore Bonapasta and M. Capizzi, Defect Dif fus. Forum 157-159, 133 (1998), and references therein.

[10] See, e.g., E. E. Haller, W. L. Hansen, and F. S. Goulding, Adv. Phys. 30, 93 (1981), and references therein.

[11] For a review, see Physics and Applications of Dilute Ni trides, edited by I. A. Buyanova and W. M. Chen (Taylor \& Francis, New York, 2004); Dilute Nitride Semiconduc tors, edited by M. Henini (Elsevier, Oxford, UK, 2005); Dilute III-V Nitride Semiconductors and Material Systems, edited by A. Erol (Springer, Berlin, Germany, 2008).

[12] I. A. Buyanova, G. Pozina, J. P. Bergman, W. M. Chen, H. P. Xin and C. W. Tu, Appl. Phys Lett. 81, 52 (2002)

[13] A. Polimeni, M. Bissiri, M. Felici, M. Capizzi, I. A. Buanova, W. M. Chen, H. P. Xin, and C. W. Tu, Phys. Rev. B 67, 201303(R) (2003).

[14] I. A. Buyanova, M. Izadifard, I. G. Ivanov, J. Birch, W. M. Chen, M. Felici, A. Polimeni, M. Capizzi, Y. G. Hong, H. P. Xin, and C. W. Tu, Phys. Rev. B 70, 245215 (2004).

[15] I. A. Buyanova, M. Izadifard, W. M. Chen, A. Polimeni, M. Capizzi, H. P. Xin and C. W. Tu, Appl. Phys. Lett. 82, 3662 (2003)

[16] D. Dagnelund, X. J. Wang, C. W. Tu, A. Polimeni, M. Capizzi, W. M. Chen, and I. A. Buyanova, Appl. Phys. Lett. 98, 141920 (2011).

[17] D. Dagnelund, I. P. Vorona, G. Nosenko, X. J. Wang, C. W. Tu, H. Yonezu, A. Polimeni, M. Capizzi, W. M. Chen, and I. A. Buyanova, J. Appl. Phys. 111, 023501 (2012). 